\title{
Reduction mammoplasty as a treatment for symptomatic central venous stenosis
}

\author{
Denise Seok Fun Fok, Janna Joethy \\ Department of Plastic, Reconstructive and Aesthetic Surgery, Singapore General Hospital, Singapore
}

Central venous stenosis is a rare cause of unilateral breast edema occurring in hemodialysis patients that needs to be differentiated from other differential diagnoses, including, but not limited to, inflammatory breast carcinoma, mastitis, lymphedema, and congestive heart failure. All reports of similar cases in the available literature have described improvement or resolution of the edema after treatment. Herein, we report and discuss the pathophysiology of breast edema formation in a patient who presented with massive left-sided breast edema 7 years after being diagnosed with central venous stenosis. Medical and minimally invasive therapy had not been successful, so she underwent reduction mammoplasty to relieve the symptoms.

Keywords Breast / Edema / Axillary vein / Upper extremity deep vein thrombosis
Correspondence: Denise Seok Fun Fok Department of Plastic, Reconstructive and Aesthetic Surgery, Singapore General Hospital, 1 Outram Road, Singapore 169608, Singapore Tel: +65-6321-4686

Fax: +65-6277-3573

E-mail: denisefok@gmail.com

We would like to acknowledge Mr. Yeo Jian Long from the Office of Singhealth Academy for providing the illustrations for this article.

Received: 6 Dec 2016 • Revised: 4 May 2017 • Accepted: 26 May 2017

pISSN: 2234-6163・ elSSN: 2234-6171 • https://doi.org/10.5999/aps.2016.02047• Arch Plast Surg 2018;45:171-176

\section{INTRODUCTION}

Central venous stenosis is a rare cause of unilateral breast edema occurring in hemodialysis patients [1], and it needs to be differentiated from other differential diagnoses, including, but not limited to, inflammatory breast carcinoma, mastitis, lymphedema, and congestive heart failure [2]. A search of PubMed using the terms "breast edema" and "central vein occlusion" resulted in 33 reported cases in the English-language literature, and all these reports have described improvement or resolution of the edema after treatment. Herein, we present a patient who had massive left-sided breast edema as a result of central venous stenosis, the pathophysiology of her condition, and the treatment that she received.

\section{CASE}

A 61-year-old Malay woman with a medical history of diabetes mellitus, hypertension, and end-stage renal disease (ESRD) presented to the Plastic Surgery clinic of Singapore General Hospital for massive lymphedema of the left breast and arm in 2014; this condition caused her pain, affected her activities of daily living, and limited her mobility. She was wheelchair-bound due to the size and weight of her breast, and had a strained relationship with her spouse as she was embarrassed about her appearance.

She was diagnosed with ESRD in 1991 and had a left brachiocephalic (BC) arteriovenous fistula (AVF) created in 1993. She subsequently received a cadaveric renal transplant in 1998, which failed in 2008, and she was re-initiated on hemodialysis.

This patient presented to the clinic with unilateral breast and upper limb swelling in late 2007; this was investigated with an ultrasound and mammogram of her breasts, as well as lymphoscintigraphy of the left upper limb (Fig. 1). Her breast investigations were unremarkable, and lymphoscintigraphy showed persistent pooling of tracer at the injection site, consistent with 


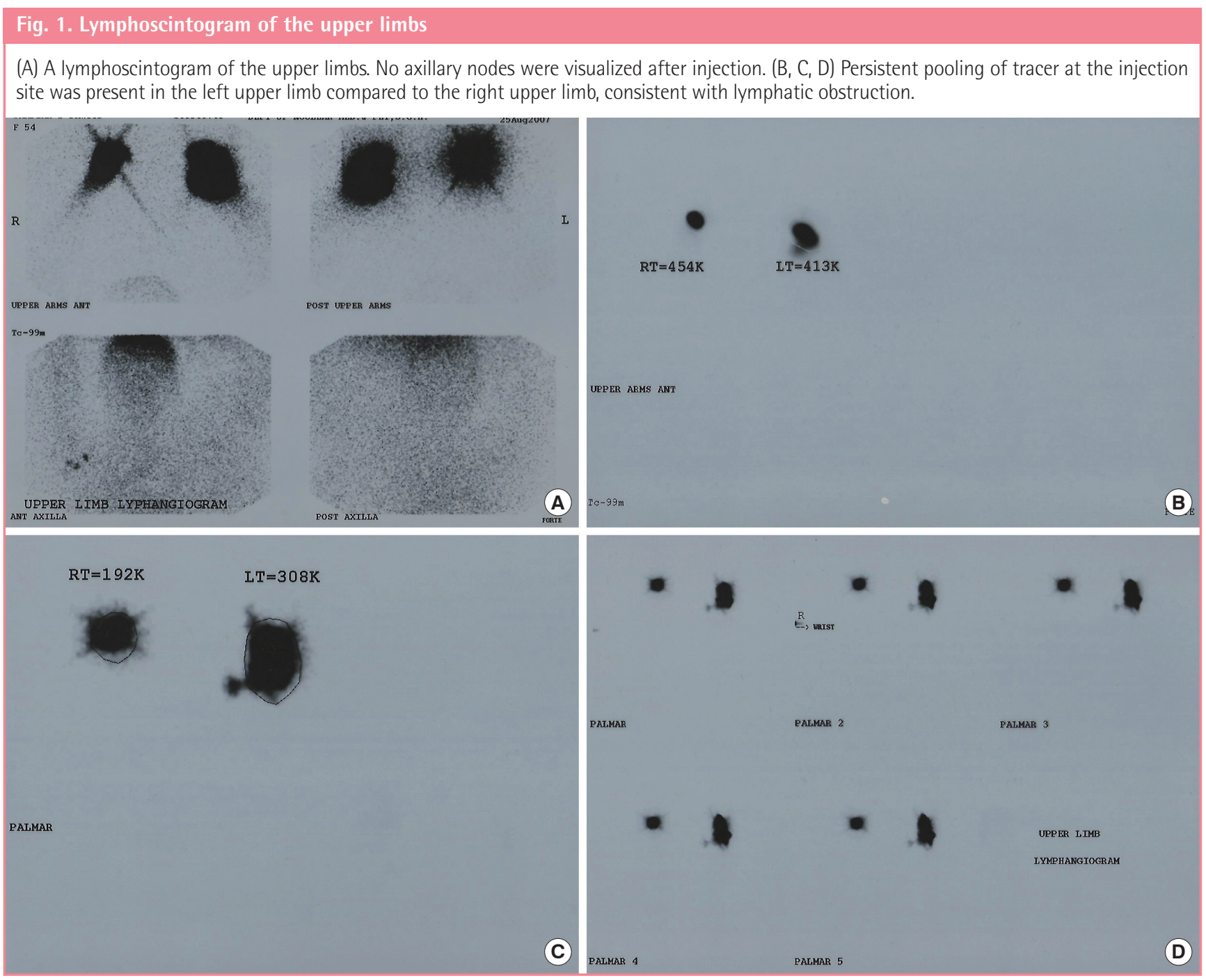

lymphatic obstruction. No axillary nodes were visualized. Her BC AVF was hypertrophied with hyperdynamic flow and was thus ligated, with the simultaneous creation of a right radiocephalic AVF.

Magnetic resonance imaging of the left brachial plexus and chest in January 2008 revealed a left axillary vein thrombosis extending slightly to the left subclavian vein. A previous fistulogram in August 2007 had shown clear central veins, and there was no central vein cannulation in the period between the 2 investigations. She completed 3 months of oral anticoagulation therapy with warfarin, but her symptoms did not improve. Central venous angioplasty showed $80 \%$ stenosis in the left brachiocephalic vein at its junction with the right brachiocephalic vein and $90 \%$ stenosis in the right subclavian vein at its junction with the right brachiocephalic vein. This was reduced to $30 \%$ and $20 \%$ residual stenosis, respectively, after balloon angioplasty.

She had repeated balloon angioplasties in the right central and upper-limb peripheral veins in 2010 and 2014, but no further

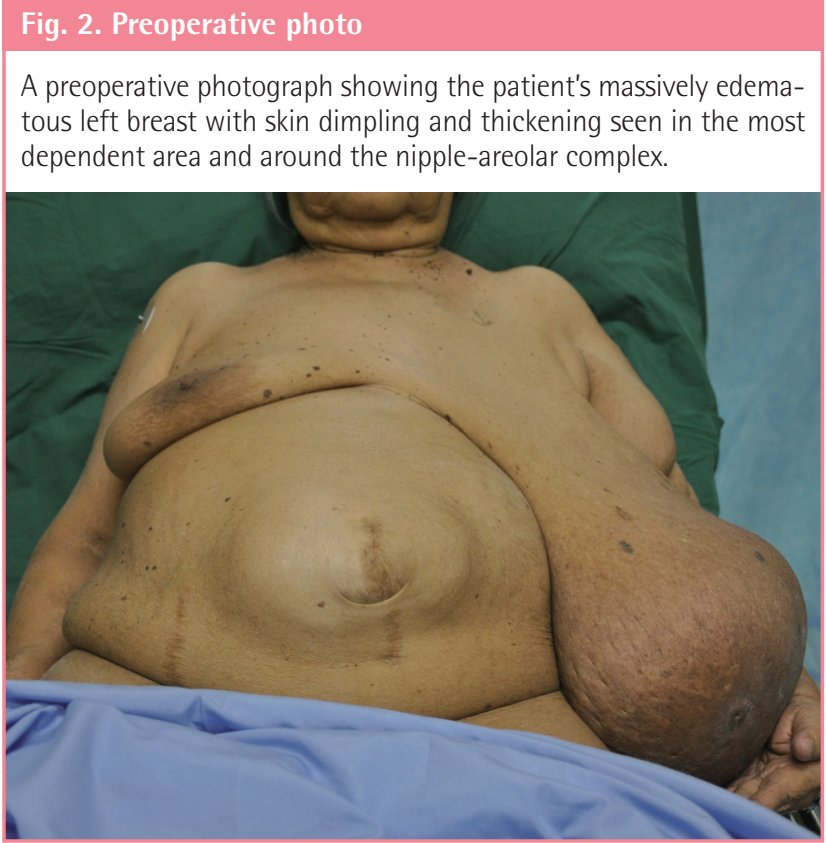




\section{Fig. 3. Resected specimen and nipple-areolar complex}

The resected breast specimen is shown here, measuring $31 \times 30 \times$

$9 \mathrm{~cm}$ and weighing $4.1 \mathrm{~kg}$. The inverted nipple-areolar complex is shown to the right of the resected breast, and the underlying edematous tissue is clearly visible.

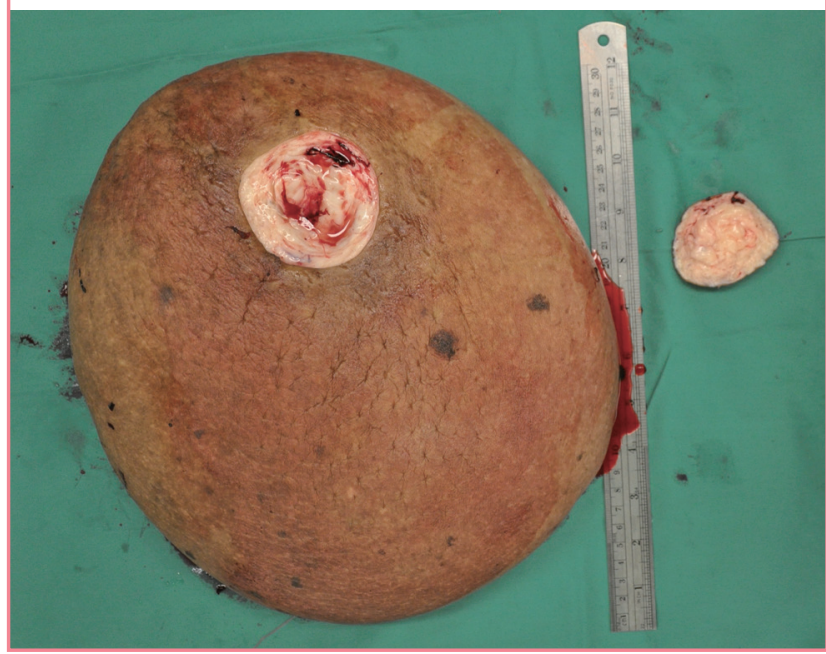

procedures on the left upper limb, as only her right upper limb vasculature was monitored for hemodialysis access.

Due to persistent breast edema that caused her chronic pain and affected her activities of daily living, she underwent reduction mammoplasty in November 2014 (Fig. 2). The resected specimen measured $31 \times 30 \times 9 \mathrm{~cm}$ and weighed $4.1 \mathrm{~kg}$. The nipple-areolar complex was discarded, as the dermis was extremely thick and unsuitable for use as a free graft (Fig. 3). Histology demonstrated changes in keeping with massive lymphedema of the breast and lymphangioma, and no evidence of malignancy. Her postoperative recovery was uneventful, and she was able to ambulate with a walking frame prior to her discharge.

At 1 year after surgery, her breast wounds were well healed, there was good symmetry, and she had progressed from being wheelchair-bound to able to ambulate with minimal aid (Fig. 4).

\section{DISCUSSION}

Unilateral breast edema is a rare complication of subclavian or brachiocephalic vein stenosis, and occurs only in hemodialysis patients with vascular access on the same side [1]. Venous drainage of the breast occurs via the internal thoracic and lateral thoracic veins. On the left side, the lateral thoracic vein drains into the axillary vein, a tributary of the brachiocephalic vein, and the internal thoracic vein drains into the left brachiocephalic vein directly (Fig. 5A). With a more distal occlusion, venous hypertension may be overcome by collaterals over the breast, leading to upper limb edema (Fig. 5B). However, with such a proxi-

\section{Fig. 4. Postoperative results}

A photograph showing the results 1 year after surgery.

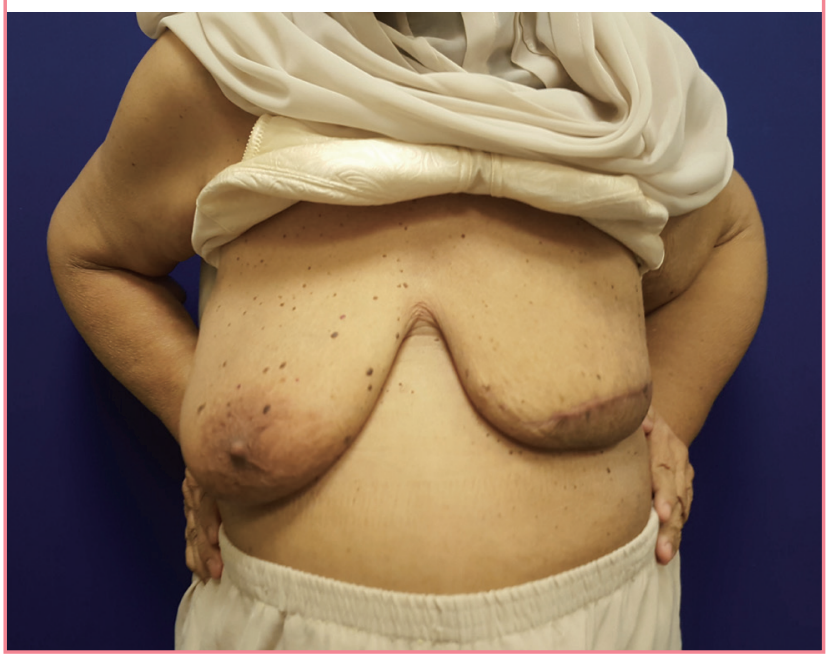

mal stenosis, venous drainage is impaired, and the breast develops edema (Fig. 5C). This is further aggravated by the presence of an AVF or arteriovenous graft (AVG) on the ipsilateral limb, which increases blood flow.

There are many causes of breast edema, and it is imperative to accurately diagnose the problem to avoid unnecessary investigations or treatment. The causes include inflammatory breast carcinoma, lymphoma, mastitis, congestive heart failure, lymphedema, central vein stenosis, fat necrosis, trauma, post-irradiation changes, granulomatous diseases, nephrotic syndrome, progressive systemic sclerosis, leukemia, and pemphigus [2].

Central venous cannulation from previous catheters is well known to cause central vein stenosis; however, rare cases of central vein stenosis without a history of cannulation have also been reported. This is thought to be due to the high flow of the fistula [20]. Treatment modalities include angioplasty with or without stent placement, embolization of the long thoracic vein [9], ligation of the AVF or AVG, veno-venous bypass [5,8], and oral anticoagulation. If these interventions fail to relieve the venous hypertension, soft tissue edema develops [1], and if persistent, may then result in secondary lymphedema of the affected breast or limb.

Our patient was proven to have central venous stenosis on imaging, and lymphedema on histology. We postulate that her breast and arm lymphedema was a result of chronic central venous stenosis and that a hyperdynamic AVF on the same side contributed to her condition.

A search on PubMed using the terms "breast edema" and "central vein occlusion" resulted in 33 reported cases in the Englishlanguage literature. Eighteen patients had minimally invasive procedures (angioplasty or embolization of the veins), 10 un- 


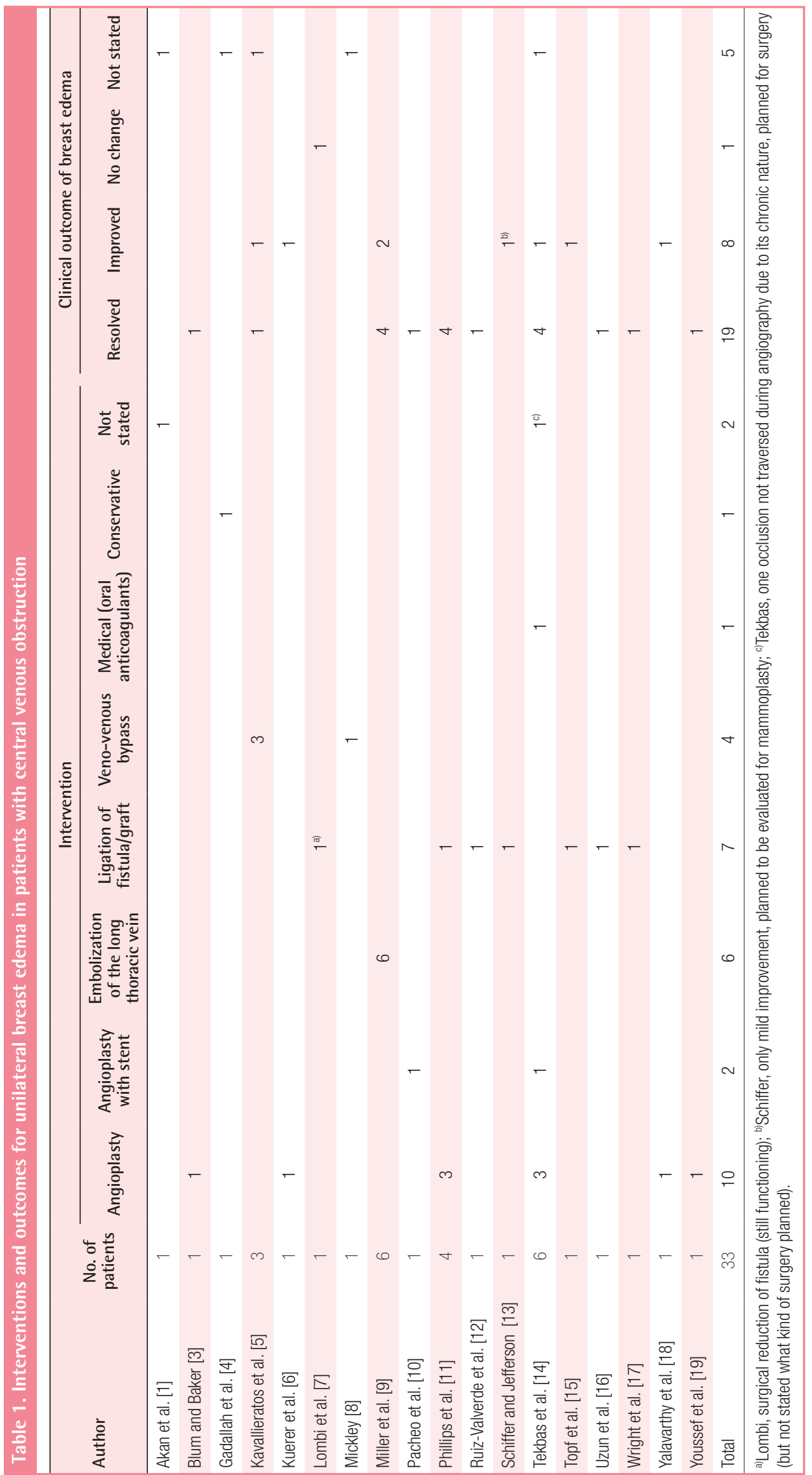




\section{Fig. 5. Normal and impaired drainage of the breast}

(A) Normal venous drainage of the left breast. The venous drainage of the left breast occurs medially via the internal thoracic vein, which then drains directly into the brachiocephalic vein, and laterally via the lateral thoracic vein, which drains into the axillary vein, a tributary of the brachiocephalic vein. (B) Distal venous occlusion in the axillary vein. The breast drains via collaterals to the internal thoracic vein, thereby overcoming venous hypertension. (C) Proximal venous occlusion in the brachiocephalic vein. Venous drainage is impaired, causing breast and upper limb edema.

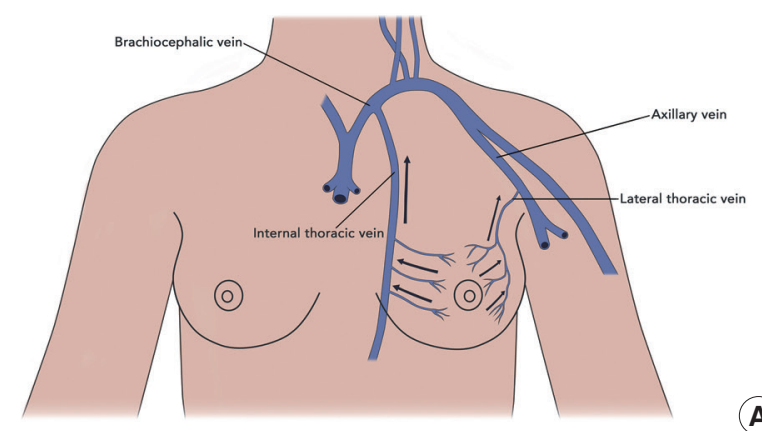

A

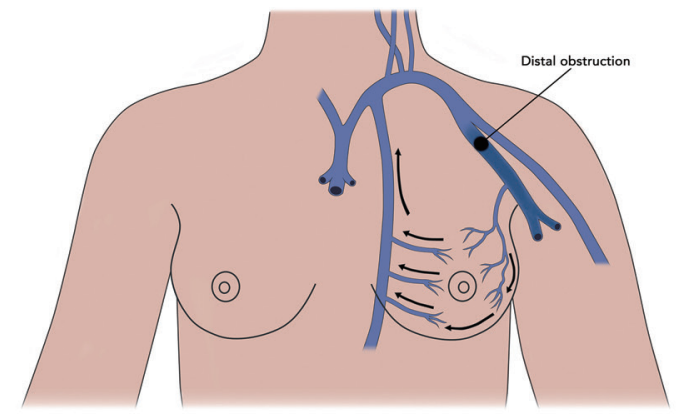

(B)

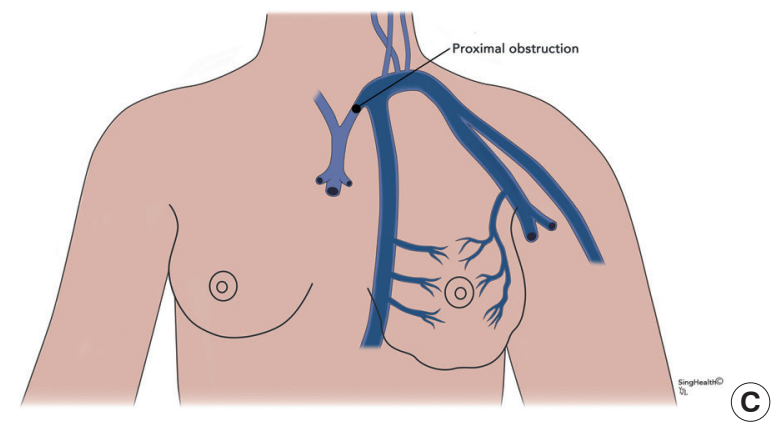

derwent surgical procedures (ligation of the AVF/AVG or bypass surgery), 1 was treated with oral anticoagulation, 1 was treated conservatively and the treatment of 2 was not described. Of the 33 reported cases, improvement or resolution of breast edema with treatment was described in 27 , while the clinical outcomes of the remaining 5 cases were not stated (Table 1) [1,3-19].

In our patient's case, breast edema failed to improve despite fistula ligation, oral anticoagulation, and balloon angioplasty. Veno-venous bypass carried a high risk of morbidity, and lymphatic surgery was unlikely to achieve a satisfactory result, as the breast was massive and unlikely to be reduced to a manageable size. As such, reduction mammoplasty was performed for symptom relief. As far as we are aware, this is the first reported case of unilateral breast edema secondary to central vein stenosis that required mammoplasty for symptom relief.

Massive breast edema can cause significant morbidity to a patient. The cause needs to be accurately diagnosed so that an appropriate and speedy intervention can ensue. In patients with breast edema secondary to central vein stenosis in whom medical or minimally invasive treatment is not successful, and in whom lymphatic or bypass surgery is not an option, reduction mammoplasty may serve as an alternative for symptom relief and improve the patient's quality of life.

\section{NOTES}

\section{Conflict of interest}

No potential conflict of interest relevant to this article was reported.

\section{Ethical approval}

The study was performed in accordance with the principles of the Declaration of Helsinki. Written informed consents were obtained.

\section{Patient consent}

The patients provided written informed consent for the publication and the use of their images.

\section{REFERENCES}

1. Akan H, Arik N, Yalin T, Malazgirt Z. Unilateral breast enlargement: a rare complication of subclavian vein catheterization for hemodialysis. Comput Med Imaging Graph 2001;25:357-9.

2. KwakJY, Kim EK, Chung SY, et al. Unilateral breast edema: spectrum of etiologies and imaging appearances. Yonsei Med J 2005;46:1-7.

3. Blum C, Baker M. Venous congestion of the breast mimicking inflammatory breast cancer: case report and review of literature. Breast J 2008; 14:97-101.

4. Gadallah MF, El-Shahawy MA, Campese VM. Unilateral breast enlargement secondary to hemodialysis arteriovenous fistula and subclavian vein occlusion. Nephron 1993; 63:351-3. 
5. Kavallieratos N, Kokkinos A, Kalocheretis P. Axillary to saphenous vein bypass for treatment of central venous obstruction in patients receiving dialysis. J Vasc Surg 2004;40: 640-3.

6. Kuerer HM, Wilson MW, Bowersox JC. Innominate vein stenosis mimicking locally advanced breast cancer in a dialysis patient. Breast J 2001;7:128.

7. Lombi F, Garcia A, Young P, et al. Unilateral breast enlargement due to a high-flux ipsilateral hemodialysis fistula. J Vasc Access 2010;11:169-70.

8. Mickley V. Central vein obstruction in vascular access. Eur J Vasc Endovasc Surg 2006;32:439-44.

9. Miller GA, Friedman A, Khariton A, Jotwani MC, Savransky Y. Long thoracic vein embolization for the treatment of breast edema associated with central venous occlusion and venous hypertension. J Vasc Access 2010;11:115-21.

10. Pacheo D, Polo JR, Lopez-Baena JA, Vega D, Echenagusia A, Ferreras I. Unilateral breast enlargement secondary to right brachiocephalic vein occlusion. Am J Kidney Dis 2000;35:E26.

11. Phillips GS, Scheel PJ Jr, Zeiger MA. Unilateral breast enlargement: four case reports of an "unusual" presentation of central vein stenosis in patients undergoing hemodialysis. Surgery 1998;123:699-701.

12. Ruiz-Valverde MP, Fort J, Camps J, Olmos A, Piera L. Unilateral breast and arm enlargement secondary to haemodialysis arteriovenous fistula without subclavian vein occlusion. Nephrol Dial Transplant 1994;9:85-6.
13. Schiffer JT, Jefferson BK. Cases from the Osler Medical Service at Johns Hopkins University. Am J Med 2003;115:404-6.

14. Tekbas G, Oguzkurt L, Gurel K, Ozkan U, Gur S, Onder H. Is unilateral breast enlargement always a sign of cancer? Hemodial Int 2011;15:553-8.

15. Topf G, Jenkins P, Gutmann FD, Rieselbach RE, Saltzstein EC. Unilateral breast enlargement: a complication of an arteriovenous fistula and coincidental subclavian vein occlusion. JAMA 1977;237:571-2.

16. Uzun M, Akkan MK, Uzun F, Karaosmanogu D. Asymmetric venous engorgement of the breast due to a high output hemodialysis fistula. J Clin Ultrasound 2009;37:163-4.

17. Wright RS, Quinones-Baldrich WJ, Anders AJ, Danovitch GM. Pleural effusion associated with ipsilateral breast and arm edema as a complication of subclavian vein catheterization and arteriovenous fistula formation for hemodialysis. Chest 1994;106:950-2.

18. Yalavarthy U, Agrawal VK, Showkat A. Unilateral breast swelling as a complication of innominate vein stenosis in a hemodialysis patient. Clin Nephrol 2011;75 Suppl 1:56-9.

19. Youssef JJ, Brown CD, Friedman EA. Asymmetric breast enlargement minus central venous thrombosis in a hemodialysis patient. Hemodial Int 2008;12:30-3.

20. Oguzkurt L, Tercan F, Yildirim S, Torun D. Central venous stenosis in haemodialysis patients without a previous history of catheter placement. Eur J Radiol 2005;55:237-42. 